\title{
Topic Study Group No. 38: Research on Resources (Textbooks, Learning Materials etc.)
}

\author{
Lianghuo Fan, Luc Trouche, Chunxia Qi, Sebastian Rezat \\ and Jana Visnovska
}

TSG38 focuses on issues related to mathematics teaching and learning resources, which mainly refer to school mathematics textbooks but also include other resources such as teacher manuals, student learning and assessment materials, and online resources. It is the hope of the organising team that TSG 38 would bring to foreground and examine various theoretical and methodological approaches used to study teaching and learning resources.

In the pre-congress call for contribution, it was stated that TSG38 sought contributions addressing broadly the areas of resources, teachers, and students, as outlined in the list of possible questions below, with a particular interest in analyses of the evolution of interactions between resources, teachers and students in a time of transition. The following three aspects were particularly highlighted in the call for contribution.

About the resources themselves: Among the learning materials available in mathematics classrooms in different countries, what role do textbooks and other curricular or learning resources play in mathematics teaching, learning, and assessment? How does the digitalization of information and communication affect this role? Is it possible to have a common definition of e-textbooks, and how could we characterize the differences between the traditional textbooks and e-textbooks?

Co-chairs: Lianghuo Fan, Luc Trouche.

Team members: Chunxia Qi, Sebastian Rezat, Jana Visnovska.

\author{
L. Fan $(\bowtie)$ \\ University of Southampton, Southampton, UK \\ e-mail: L.Fan@southampton.ac.uk \\ L. Trouche \\ École Normale Supérieure de Lyon, Lyon, France \\ e-mail: luc.trouche@ens-lyon.fr \\ (C) The Author(s) 2017 \\ G. Kaiser (ed.), Proceedings of the 13th International Congress on Mathematical \\ Education, ICME-13 Monographs, DOI 10.1007/978-3-319-62597-3_65
}


About the teachers: What are the main features of the teacher resource systems in different countries, their crucial resources, stability, flexibility and evolutions? What are the relationships between their individual and collective resources, and how could we model such relationships? What about the relationships between resource designers and users? What are the consequences of evolutions at stake for the teaching of mathematics, and for teacher knowledge and professional development?

About the students: what are the main features of the student resource systems in different countries? What is the effect of modern ICT (particularly internet) on their use and the design of resources? How do these evolutions affect their behavior, learning and relationships concerning the subject of mathematics?

TSG38 received a larger-than-expected number of submissions. According to the statistics released, it was one of the five largest TSGs in terms of the number of submissions received. After the process of review, 67 contributions were accepted, 61 for oral presentation and 6 for poster presentation.

Given the large number of contributions, the programme of TSG38 was organised into four 90-min regular sessions, plus 10 concurrent parallel sessions which took place in 4 time slots. As Sebastian Rezat was unable to attend the congress due to some unforeseen reason, these sessions were chaired by the two chairs, the two team members and the IPC liaison person Birgit Pepin. The four regular sessions are as follows:

Session 1 (26 July 2016). Setting the scene: What role do textbooks and other curricular or learning resources play in mathematics teaching, learning, and assessment? (Chair: Birgit Pepin)

1.1 Remillard, J.: Understanding teacher-resource interactions: Perceiving curriculum resources (Contribution invited).

1.2 Leshota, M. J., and Adler, J.: Disaggreating a mathematics teacher's pedagogical design capacity.

1.3 Fan, L., Mailizar, M., Alafaleq, M., and Wang, Y.: How proof is presented in selected secondary maths textbooks in China, Indonesia and Saudi Arabia.

1.4 Qi, C., Zhang, X., and Huang, D.: Research on textbooks used in teaching transformation for secondary school.

Session 2 (27 July 2016). How does the digitalization of information and communication affect the role of resources? (Chair: Jana Visnovska)

2.1 Trouche, L., Gueudet, G., and Pepin, B.: Open educational resources: A chance for enriching mathematics teacher's resource systems?

2.2 Kynigos, C., and Kolovou, A.: Teachers as designers of digital educational resources for creative mathematical thinking.

2.3 Pu, S., Song, N.: Research on international development trends of primary mathematics textbooks in the 21 st century.

2.4 Rocha, K.: Uses of online resources and documentational trajectories: The case of Sésamath. 
Session 3 (29 July 2016). Teachers' collective work through resources (Chair: Chunxia Qi)

3.1 Van Steenbrugge, H., Larsson, M., Ryve, A., Insulander, E., \& Brehmer, D.: Curriculum support for teachers: A collective perspective.

3.2 Faughn, A. P., and Borchelt, N.: Mathematics teachers' circles: a resource perspective on classroom transfer.

3.3 Wang, C.: Analyzing teachers' expertise, resources and collective work throughout Chinese and French windows.

3.4 Essonnier, N., Kynigos, C., Trgalova, J., and Daskolia, M.: Studying the role of context in social creativity for the design of digital resources.

\section{Session 4 (30 July 2016). Teachers' and students' interactions through resources (Chair: Lianghuo Fan and Luc Trouche)}

4.1 Ruthven, K.: Researching instructional activity and student interaction with digital resources (Contribution invited).

4.2 Visnovska, J., and Cortina, J. L.: Resources as a means of supporting teachers in planning for interactions with students' ideas.

4.3 Naftaliev, E.: Engagements of prospective teachers with e-textbook.

4.4 Kim, O. K.: Teacher decisions on lesson sequence and their impact on opportunities for students to learn.

The 10 parallel sessions in 4 time slots (TS), the first two on 26 July and the last two 29 July, were organised with focuses on different areas concerning the research of mathematics textbooks and resources.

On 26 July, TS1 (60 $\mathrm{min})$ consisted of 3 parallel sessions: the first parallel session focusing on "Textbook analysis and comparison" (Chair: C. Qi; presenters: X. Yang, M. S. Aguilar, S. Y. Jeong, and K. Oh), the second on "Text evaluation and digital tools" (Chair: L. Trouche; presenters: H.-D. Janetzko, A. $\mathrm{Pu}$, and A. M. Bijura), and the third on "Teachers' work and learning with tools" (Chair: J. Visnovska; presenters: R. Lucena, R. Yap, and R. M. A. Filho). TS2 (90 min) consisted of 2 parallel sessions: the first parallel session focusing on "Problem solving" (Chair: L. Fan; presenters: E. Bingobali*, E. Santaolalla, S. Walter, and C. A. Fuentes) and the second on "Representation and illustration in textbooks" (Chair: B. Pepin; presenters: X. Liu, P. Pausigere, V. Sarveswary, R. E. Borba, V. C. Lianos, and G. Glasnovic).

On 29 July 2016, TS3 (60 min) consisted of 3 parallel sessions with all focusing on "Students and teachers": the first parallel session had three presentations (Chair: J. Visnovska; presenters: N. Podevano, X. Jia and L. Zhao), the second parallel sessions had four presentations (Chair: L. Trouche; presenters: V. Gitirana, I. Ercan, E. Benitez, and X. Shao), and the third also four presentations (Chair: L. Fan; presenters: Z. Zhu, C. C. Assis, M. Ribeiro, and M. A. Huntley). TS4 (90 min) consisted of 2 parallel sessions: the first parallel session focusing on "Collective work" (Chair: C. Qi; presenters: C. Qi, A. Bapat, S. Basturk, J. Slisko, and D. Wijayanti) and the second on "Teacher use and interaction with resources" 
(Chair: L. Trouche; presenters: H. Siedel, F. Bifano, D. Paez, L. Jaber, L. Ahl, and E. Aydin*).

The two presentations marked with * by E. Bingobali and E. Aydin were made through video presentations due to the fact that they were unable to attend the congress due to unforeseen reasons taking place in Turkey.

To conclude, it is worth noting that ICME-10 was the first congress in the history of the ICMEs that a group with specific focus on mathematics textbooks (including learning and teaching materials), Discussion Group 14, was programmed. According to the organisers, DG14 received a much smaller number of submissions and accepted only 9 of them for presentation (Fan, Turnau, Dole, Gelfman, \& Li, 2008). Compared with about nearly 70 presentations, it signals to us a clear and rapid growth of the interest of the international mathematics education community in the area of mathematics textbooks and resources (also see Fan, Zhu, \& Miao, 2013), taking into account digital evolutions (Pepin, Gueudet, Yerushalmy, Trouche, \& Chazan, 2015). On the other hand, it should be also noted that among all the submissions, a great majority of studies reported are on textbooks (compared to other resources), on teaching resources (compared to learning resources) and on printed text (compared to digital form), while methodologically, most are on textbook analysis, textbook comparison and teachers' use and interaction with textbooks and resources.

Overall, we are encouraged by the fact that there were so many contributions to TSG38 and wish to thanks all the contributors, presenters, reviewers, and the participants to help TSG38 a success. A post-congress monograph, based on contributions and presentations at TSG38, will be published by Springer.

\section{References}

Fan, L., Turnau, S., Dole, S., Gelfman, E., \& Li, Y. (2004). DG 14: Focus on the development and research of mathematics textbooks. In M. Niss (Ed.), Proceedings of the 10th International Congress on Mathematical Education (pp. 485-489). Roskilde, DK: Roskilde University.

Fan, L., Zhu, Y., \& Miao, Z. (2013). Textbook research in mathematics education: Development status and directions. ZDM-International Journal on Mathematics Education, 45(5), 633-646.

Pepin, B., Gueudet, G., Yerushalmy, M., Trouche, L., \& Chazan, D. (2015). E-textbooks in/for teaching and learning mathematics: A potentially transformative educational technology. In L. English \& D. Kirschner (Eds.), Third handbook of research in mathematics education (pp. 636-661). New York: Taylor \& Francis.

Open Access Except where otherwise noted, this chapter is licensed under a Creative Commons Attribution 4.0 International License. To view a copy of this license, visit http://creativecommons. org/licenses/by/4.0/.

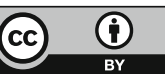

